Rabaska

Revue d'ethnologie de l'Amérique française

\title{
Michel Valière (1941-2019)
}

\section{Catherine Robert}

Volume 17, 2019

URI : https://id.erudit.org/iderudit/1066022ar

DOI : https://doi.org/10.7202/1066022ar

Aller au sommaire du numéro

Éditeur(s)

Société québécoise d'ethnologie

ISSN

1703-7433 (imprimé)

1916-7350 (numérique)

Découvrir la revue

Citer ce document

Robert, C. (2019). Michel Valière (1941-2019). Rabaska, 17, 279-282.

https://doi.org/10.7202/1066022ar

Ce document est protégé par la loi sur le droit d'auteur. L'utilisation des services d'Érudit (y compris la reproduction) est assujettie à sa politique d'utilisation que vous pouvez consulter en ligne.

https://apropos.erudit.org/fr/usagers/politique-dutilisation/ 


\section{Nécrologie}

\section{Michel Valière (1941-2019) ${ }^{1}$}

Né à Paris, il a relaté l'histoire de sa famille maternelle dans un article paru en $2010^{2}$. Il passe son enfance et sa jeunesse à Lespignan (Hérault).

Après des études de sciences physiques à Poitiers, il est nommé enseignant au collège de Gençay (Vienne) où son épouse est elle-même professeur de français et latin en 1964.

Dès 1965, ils se lancent dans la collecte de chants et danses poitevines lors de veillées villageoises. Ce premier cercle d'informateurs et d'amis sera le moteur d'une mise en valeur de savoirs musicaux délaissés. L'édition de disques et les représentations musicales théâtrales suivront. En effet, tout en assurant son enseignement de physique et de mathématiques, il collecte sans

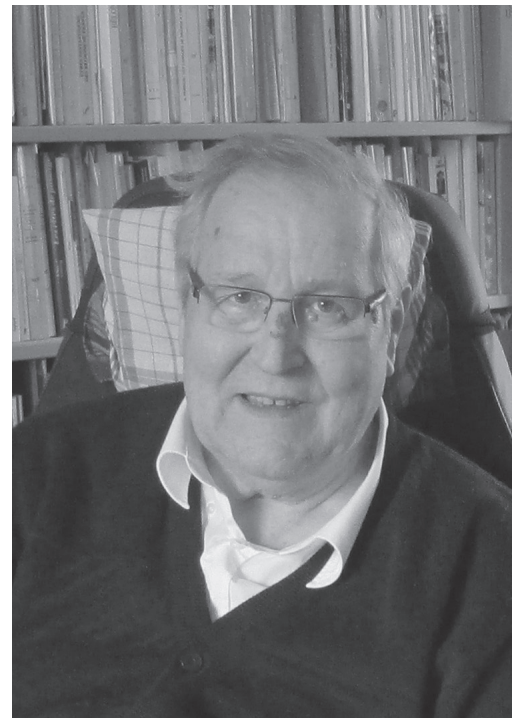

Michel Valière

Photo : Jean-Pierre Pichette,

22 novembre 2016 relâche tout élément matériel portant témoignage de la culture rurale ainsi que toute forme de littérature orale auprès des anciens avec le souci permanent

1. NDLR. Le regretté Michel Valière s'est constamment intéressé à la tradition orale de l'Amérique française et il a même accueilli chez lui plusieurs chercheurs d'ici. Entre 2008 et 2014, il a tenu à collaborer régulièrement à la revue Rabaska en y publiant articles et comptes rendus; certaines de ses œuvres y ont aussi été recensées. C'est pourquoi nous avons demandé à sa collaboratrice Catherine Robert de résumer sa carrière et de lui rendre ainsi respectueusement hommage.

2. «Ils ont passé le Sègre... : projection d'une famille migrante catalane jusqu'en PoitouCharentes ", dans Migrants et immigrés en Poitou-Charentes d'hier à aujourd'hui, Saintes, Le Croît vif, 2012, p. 413-420. 
de restituer le résultat de ses recherches par des publications et d'assurer la conservation des objets et des enregistrements réalisés.

En 1971, lors de son détachement auprès du ministère de la Jeunesse et des sports, il reprend un cursus universitaire en lettres et linguistique à l'Université de Poitiers, assiste régulièrement aux cours d'études médiévales (Pierre Bec), puis obtient le CAPES de lettres en 1978. Il enseigne alors le français dans différents établissements scolaires tout en poursuivant ses enquêtes en collaboration avec de nombreux chercheurs (dont Jean-Louis Fossat, Liliane Jagueneau).

Nommé au premier Conseil du patrimoine par le Ministre de la Culture en avril 1980, il est détaché en tant qu'ethnologue à la région Poitou-Charentes auprès de la Direction régionale des Affaires culturelles en 1981. Cette reconnaissance bien méritée intervient après la publication de deux ouvrages dans la collection « Récits et contes populaires » chez Gallimard et d'Amours paysannes chez Stock dont le succès ne s'est pas démenti.

Membre de plusieurs sociétés savantes, il s'entoure d'une équipe plus ou moins formelle de passionnés, les incitant à faire ou reprendre des études et les encourageant à s'inscrire dans un parcours de recherche ethnologique à l'École des hautes études en sciences sociales (sous la direction de Daniel Fabre) ou dans des universités. On peut citer Jean-Jacques Chevrier avec son étude sur les jeux et jouets, Jacques Chauvin sur la chaussure, Daniel Bourdu sur les tensions sociales d'Ancien régime en Poitou, ou moi-même sur la prière populaire.

Professeur associé à l'Université de Poitiers, il crée l'enseignement de l'ethnologie au sein de cette université et travaille avec des chercheurs de différentes disciplines : sociologues (Gilles Férréol, Annie Guédez et Francis Dupuy), linguistes, musicologues, psychiatres... Il encadre de nombreux travaux d'étudiants, les invitant à communiquer lors des colloques qu'il organise au sein d'associations : Société d'études folkloriques du CentreOuest (SÉFCO), Association régionale pour la promotion de l'ethnologie en Poitou-Charentes (ARPE).

Animateur dans l'âme, il fonde en 1964 La Marchoise, devenue plus tard Centre culturel-La Marchoise, groupe de danses, musiques et chants, puis cofonde avec André Pacher 1'Union Poitou-Charentes pour la culture populaire en 1969. Lors de sa présidence, en 1980, il crée Geste éditions, branche éditoriale de l'association. Très tôt, pour se former, il échange avec les représentants des musées (dont Roger Lecotté, Georges Henri Rivière et Carmen Roy) et autres institutions en France, en Acadie et au Québec, sans oublier les membres des associations relevant de la culture populaire à l'exemple de la SÉFCo (Daniel Hervé). 
Particulièrement attaché à l'enquête de terrain et à la collecte des données - indispensables au travail de l'ethnologue -, Michel Valière initie quantité de chercheurs au travail ethnographique. Entre autres, de nombreux universitaires canadiens (Ronald Labelle, Charlotte Cormier, Georges Arsenault) ont ainsi pu profiter de son expérience lors de leurs visites à Gençay.

Dans son parcours, on peut retenir parmi ses sujets de recherche et ses publications $^{3}$ : l'indispensable linguistique avec des travaux sur le poitevin et l'occitan (L'Occitan parlé à Lespignan (Hérault) : la langue des viticulteurs, Université de Toulouse, 1976). Aujourd'hui encore, un lexique sur le parler de Saint-Junien (Haute-Vienne) est en cours d'achèvement.

Son intérêt pour la littérature orale ne s'est jamais démenti, spécialement pour le conte populaire auquel il a consacré de nombreuses études : de l'étude des variantes d'un conte-type à la rédaction de commentaires typologiques dans les éditions de collecte de ses amis, de l'édition de répertoires de conteuses ${ }^{4}$ à la synthèse que constitue Le Conte populaire : approche socioanthropologique paru chez Colin en 2005. Bien sûr, il ne s'est pas désintéressé des autres genres : à la chanson dont son épouse - et interprète - a fait sa spécialité ${ }^{5}$, aux comptines, proverbes, prières... L'édition de récits de vie a aussi été l'objet de ses préoccupations ${ }^{6}$.

Afin d'assurer une restitution " plus vivante » de la société rurale au public, il a activement accompagné les réalisations cinématographiques ${ }^{7}$ et encouragé la création de films ethnographiques ${ }^{8}$.

Enfin, il a sensibilisé le grand public aux réalisations de produits artisanaux d'exception (les jours d'Angles ${ }^{9}$ ou les instruments du luthier Laurent Gayraud) valorisant les savoir-faire menacés de disparition, et a

3. Il se plaisait à dire qu'il n'avait fait que répondre à des commandes comme à celles de Christine Bonneton pour ses encyclopédies régionales.

4. Tels celui de Marie Prieur, « Une conteuse populaire poitevine, Marie Prieur », Mémoire de maîtrise, Poitiers, 1974 ; celui de Juliette Septier (en collaboration avec Geneviève Debiais) dans Récits et contes populaires du Berry, Gallimard, 1980 ; ou celui de Marie Vidaud (en collaboration avec Nicole Pintureau) dans Paroles d'Or et d'Argent, La Couronne, C.D.D.P., 1994.

5. À titre d'exemple, ils ont participé à deux ouvrages collectifs dont un en hommage à Conrad Laforte, "M'amie, faites-moi un bouquet... » coédité par Les Presses de l'Université Laval (collection " Archives de folklore » 30) et les Éditions Charlevoix en 2011 et l'autre, L'Invention du terrain en Amérique française en hommage à Marius Barbeau par la Société québécoise d'ethnologie en 2015 (Rabaska, vol. 13).

6. Cf. Marcelino Ferrer, Camino : itinéraire d'un réfugié politique républicain espagnol et Marie-Thérèse et Vincent Peltier, Nous n'avons pas fini de marcher, Limoges, CIPA, respectivement publiés en 1994 et 1998.

7. Terre d'amitié réalisé en cinéma direct par André Gladu et Michel Brault en 1978 a été classé « Mémoire du monde » par l'Unesco en 2017.

8. Cf. Marion Valière-Loudiyi, Le Plus beau des jouets, 2000, et Ménétriers du Poitou, 2005.

9. Monique Leyssène et M.V., Les Jours d'Angles, Paris, C. Bonneton, 1984 ; ainsi que plusieurs articles dont « L'Invention féminine à Angles-sur-l'Anglin (Vienne) » paru dans Ethnologie française, $\mathrm{n}^{\circ} 1$ de 1989 , p. 27-37. 
attiré l'attention sur les productions d'art populaire ${ }^{10}$.

Dans le cadre institutionnel, Michel Valière a également beaucoup œuvré pour la reconnaissance, la protection et la mise en valeur du « petit patrimoine » (lavoirs, fours, écluses à poissons, petits commerces, cabanes de cantonnier, moulins $)^{11}$ et du patrimoine industriel ${ }^{12}$ en France, accompagnant sur le terrain projets et réalisations. Dans Ethnographie de la France ${ }^{13}$, outre l'apport classique de la discipline, il présente l'usage social de l'ethnologie ainsi que sa place dans diverses institutions (écomusées, parcs régionaux, collectivités territoriales) en s'appuyant sur ses propres recherches et son expérience socioprofessionnelle.

Conjuguant le questionnement incessant de l'ethnographe à la précision linguistique, le raisonnement de l'ethnologue à l'écriture littéraire, Michel Valière a mis en valeur toute la richesse des savoirs populaires du Poitou rural et de quelques autres communautés. Pour en conserver la mémoire, son fonds d'enregistrements sonores est en voie de numérisation aux Archives départementales de la Vienne.

Dès l'annonce de son décès, les messages ont afflué, témoignant de l'importance de son réseau de connaissances et rappelant sa culture, sa bienveillance et sa générosité, mais aussi son exigence.

CATHERINe Robert Présidente de l'ArPE, Saint-Junien

10. Il a participé à la sauvegarde du « Jardin de Gabriel » à Nantillé (Charente-Maritime). Ce jardin de statues est aujourd'hui reconnu comme un chef-d'œuvre de l'art brut.

11. Cf. « Partenaires nouveaux ou Patrimoine du $3^{\mathrm{e}}$ type ou tiers ordre ou laissé-pour-compte » dans Transferts, $\mathrm{n}^{\circ} 14-15,1991$, p. 28-29.

12. Virginie Kollmann et M.V., Le Patrimoine industriel, $2^{\mathrm{e}}$ éd., Poitiers, Agence de coopération des bibliothèques Poitou-Charentes et ARPE, 1992.

13. Ethnographie de la France : histoire et enjeux contemporains des approches du patrimoine ethnologique, Paris, A. Colin, 2002. 